\title{
Estratégia\&Negócios
}

ISSN 1984-3372

http://www.portaldeperiodicos.unisul.br/index.php/EeN/

\section{MODELO DE LIDERANÇA DE PESSOAS PARA SIMULADORES DE GESTÃO}

MODEL OF LEADERSHIP OF SIMULATORS FOR PEOPLE MANAGEMENT

\section{Juliano Zaffalon Gerber}

Pós-Doutorado, Doutorado e Mestrado em Engenharia de Produção - UFSC.

Graduação em Análise de Sistemas - UCPEL.

E-mail: juliano_zg@hotmail.com.

\section{Rodrigo Gabriel de Miranda}

Doutorado e Mestrado em Engenharia de Produção - UFSC. Graduação em Engenharia de Produção Elétrica - UFSC. E-mail: rgabrieldemiranda@yahoo.com.br

\section{Antonio Cezar Bornia}

Doutorado e Mestrado em Engenharia de Produção - UFSC.

Graduação em Engenharia Mecânica - UFPR.

E-mail: cezar@deps.ufsc.br

\section{Andréa Cristina Trierweiller}

Pós-Doutorado, Doutorado, Mestrado e Especialização em Engenharia de Produção - UFSC.

Graduação em Administração - UFSC.

E-mail: andreatri@gmail.com

Recebido em 27/07/2011. Aprovado em 05/10/2011. Disponibilizado em 03/12/2011.

Avaliado pelo Sistema double blind review

R. eletr. estrat. neg., Florianópolis, v.4, n.2, p. 181-201, jun./dez. 2011

http://portaldeperiodicos.unisul.br/index.php/EeN/index
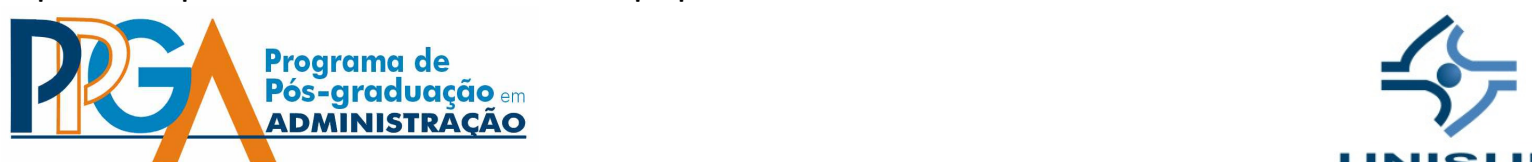

UNISUL

CCopyright 2008 UNISUL-PPGA/Estratégia e Negócios. Todos os direitos reservados. Permitida citação parcial, desde que identificada a fonte. Proibida a reprodução total. Em caso de dúvidas, consulte o editor:

ademar.unisul@gmail.com; (48) 3229-1932 


\section{RESUMO}

No ensino das práticas de gestão empresarial, os simuladores gerenciais exercem um papel de destaque, principalmente quando o objetivo é utilizar instrumentos didáticos e ferramentas de ensino-aprendizagem envolventes, práticos e dinâmicos. 0 universo de versões de simuladores e de áreas de gestão por eles abordadas é amplo, no entanto, versões que contemplam apenas áreas exatas da administração ainda são observados com mais freqüência, negligenciando, pois, os aspectos humanos de uma gestão empresarial. Diante disso, este artigo apresenta um modelo destinado a simuladores computacionais de gestão de empresas, cujo objetivo é o de proporcionar aos participantes o desenvolvimento de habilidades e competências gerenciais relacionados à liderança de pessoas. Para tal propósito, foram investigadas técnicas e práticas de liderança de pessoas com potencial de modelagem computacional e foram elaborados um modelo e um processo de tomada de decisões para simuladores de gestão. $\mathrm{O}$ artigo segue com a apresentação de um estudo de caso e é finalizado com os resultados e conclusões.

Palavras Chave: simuladores empresariais. Comportamento humano. Liderança.

\section{INTRODUÇÃO}

Ao longo do tempo, observa-se o avanço e consolidação dos simuladores de empresas computacionais como instrumentos didáticos e ferramentas de ensinoaprendizagem eficazes no desenvolvimento das boas práticas gerenciais nos mais variados ambientes organizacionais. Em boa parte, isso se deve às constantes pesquisas que proporcionam manutenções, ajustes nas dinâmicas, inovações tecnológicas e adequações dos modelos às principais teorias de gestão. No entanto, embora os simuladores de gestão sejam ferramentas que propiciam aos participantes a capacitação e o desenvolvimento de 
habilidades e competências por intermédio da teoria-prática, observa-se que uma boa parcela dos modelos abordam segmentos da gestão, privilegiando o desenvolvimento dos participantes em áreas exatas como marketing, finanças, produção e/ou logística ou somente em aspectos voltados puramente à gestão humana.

Neste contexto, este artigo apresenta um modelo para simular a função de líder de pessoas, a ser incorporado a simuladores computacionais de gestão empresarial que contemplam apenas áreas exatas da administração, com o propósito de proporcionar aos participantes a percepção, o exercício e o aprendizado, não somente de habilidades gerenciais técnicas, mas também habilidades menos tangíveis como liderança e gestão de pessoas.

Entende-se que o propósito deste estudo alinha-se com os anseios de muitos pesquisadores, professores e coordenadores de cursos de administração e engenharia que propagam a idéia que os programas formadores de gestores empresariais devam contemplar tanto a formação tecnológica, quanto a formação humana (NAVARRO, 2004; COUTU, 2004; DORIA; ROZANSKI; COHEN, 2004; REIS; SILVA, 2004). Diante disso, este artigo investiga técnicas e práticas de liderança de pessoas com potencial de modelagem computacional, sugere um modelo e um processo de tomada de decisões envolvendo a liderança de pessoas para simuladores de gestão, e apresenta um caso de um simulador.

\section{MÉTODO DE PESQUISA}

Analisado pelas perspectivas de Silva e Menezes (2005), este trabalho pode ser classificado da seguinte forma: quanto à sua natureza, este trabalho é uma Pesquisa Aplicada, pois objetiva gerar conhecimentos para aplicações práticas dirigidas à solução de problemas específicos. Do ponto de vista de seus objetivos este estudo é classificado como Pesquisa Exploratória, pois visa proporcionar maior familiaridade com o problema com vistas a torná-lo explícito e a construir hipóteses. 
Quanto aos procedimentos metodológicos, nesta primeira etapa buscou-se desenvolver uma estrutura conceitual básica que permitisse a reflexão acerca dos aspectos envolvidos no papel do líder nas organizações, identificando-o como recurso estratégico; além de técnicas e práticas com potencial de serem modelados num simulador de gestão empresarial. De posse dos levantamentos teóricos, encaminhou-se à etapa seguinte, caracterizada pelo desenvolvimento de novas proposições de método e de ferramentas de liderança, além de uma estratégia organizacional voltada à simulação que define o ciclo de tomada de decisões do líder num simulador. Finalmente foi realizado um estudo de caso em um jogo de empresas consolidado no meio acadêmico.

Identifica-se na literatura um número significativo de estudos relacionados à liderança de pessoas, grande parte reforçam a compreensão de que um gestor convive com a missão de obter resultados por intermédio de pessoas e necessita de habilidades, competências, técnicas e ferramentas úteis a este propósito (JUCHEM; ROSSATI; GOMES, 2011; FIATES; NASCIMENTO; FIATES, 2009; FREAS; SHERMAN, 2004; FIORELLI, 2003; BIGDON; KORF, 2004; HESSELBEIN; COHEN, 1999; NELSON, 1991). Neste contexto, surgem as questões: Como liderar de forma eficaz em prol do alto desempenho dos subordinados? É possível desenvolver um modelo computacional que permita simular o processo de liderança de pessoas? Em busca destas respostas, trilhou-se um número expressivo de caminhos. Marshal Goldsmith e Bert Decker em Goldsmith, Lyons e Freas (2000), defendem feedback's como instrumentos para alinhar o comportamento das pessoas com os valores da empresa; Laner e Cruz Jr. (2004), apresentam o processo de empowerment como transferência de autoridade e responsabilidade para aumentar o envolvimento e o comprometimento dos colaboradores às tomadas de decisões; Barbeiro (2003) defende a comunicação como função básica da liderança, pois permite canalizar as emoções coletivas numa direção positiva; Gerstberger e Gromala (2010) e Nelson (1991), sugerem o sistema PRICE (Pinpoint-Localizar, Record-Registrar, Involve-Envolver, Coach-Monitorar e EvaluateAvaliar), como um modelo para estabelecer controles à monitoração de desempenho dos liderados; Bell (2000) apresenta o Mentoring como um programa pelo qual o líder ajuda um colaborador a aprender algo que aprenderia não tão bem, mais lentamente, ou simplesmente não aprenderia, se deixado por conta própria; Porché e Niederer (2002), R. eletr. estrat. neg., Florianópolis, v.4, n.2, p. 181-201, jun./dez. 2011 
apresentam o processo Coaching como modelo que agrega métodos, ferramentas e práticas de liderança com a finalidade de elevar o desempenho das pessoas. Para Goleman (2004), embora certas destrezas técnicas e analíticas sejam requisitos básicos para o sucesso do líder, a Inteligência Emocional talvez seja o principal diferencial de um líder de alto desempenho; Belasco e Stayer (1994) apresentam como solução de liderança o Modelo LTJ Leading The Journey que consiste em fazer com que os outros se guiem pelo pensamento estratégico e pela concentração nas direções certas, removendo obstáculos, desenvolvendo responsabilidades e executando ações autodirigidas. Preconizado por Goldsmith, Lyons e Freas (2000), o modelo de Liderança Situacional de Paul Hersey, também aponta para a direção da autogestão e parte do pressuposto de que, quanto mais o líder adapta seu estilo de comportamento para atender a particular situação e as necessidades dos liderados, de forma mais eficiente o liderado conseguirá atingir os objetivos pessoais e organizacionais.

Por suas características, aspectos estratégicos e processos observou-se que o modelo de Liderança Situacional, contribui às proposições deste trabalho, motivo pelo qual será apresentado em maiores detalhes no tópico seguinte.

\section{LIDERANÇA DE PESSOAS PARA SIMULADORES DE GESTÃO}

Um dos estudos de destaque, que se renova e atualiza, encaixando-se ao propósito da liderança de pessoas para simuladores computacionais de gestão, tal como é pretendido neste estudo, é a teoria sobre Liderança Situacional de Paul Hersey (GOLDSMITH; LYIONS; FREAS, 2000 e 2003; HERSEY; BLANCHARD, 1986 e 1996).

Entende-se que esta teoria é adequada por diversas razões, entre elas destacamse: objetividade: em uma organização dificilmente encontram-se psicólogos nos cargos de gerentes e diretores, portanto, existe pouco espaço para análises psicológicas aprofundadas; praticidade: a liderança situacional é prática, pois apresenta métodos relativamente simples, com poucos elementos, capacitando um líder a definir uma ação aos seus subordinados com bastante eficácia; adaptabilidade à modelagem matemática: no modelo o nível de 
prontidão dos subordinados a uma tarefa é classificado de forma objetiva e as ações do líder limitam-se a esta classificação; versatilidade: a liderança situacional poder ser utilizada isoladamente ou associada a outras técnicas de liderança, como por exemplo, o coaching e o mentoring.

Encontra-se no processo da Liderança Situacional a busca do ato de delegar que, dentre as habilidades gerenciais relacionadas com a liderança de pessoas, é sem dúvidas um destaque. Ao delegar com eficácia o gerente obtém mais tempo, se concentra em atividades de maior relevância ao seu cargo e aumenta seu potencial de promoção. Além dos indivíduos, as equipes também são beneficiadas com o ato de delegar, pois seus membros aumentam o envolvimento nos projetos e desenvolvem novas habilidades. Do ponto de vista das organizações, o ato de delegar pode aumentar a qualidade, maximizar o rendimento eficiente, diminuir desperdícios nos processos produtivos, produzir decisões mais rápidas e eficazes e elevar o moral das pessoas (GERSTBERGER; GROMALA, 2010; BIGDON; KORF, 2004; HESSELBEIN; COHEN, 1999; NELSON, 1991).

Por estes motivos, são apresentados neste tópico, elementos e mecanismos que auxiliam o líder no ato de delegar de forma eficaz. Considera-se para esta pesquisa, as teorias apresentadas por Paul Hersey sobre o modelo de Liderança Situacional (GOLDSMITH; LYIONS; FREAS, 2000 e 2003; HERSEY; BLANCHARD, 1986 e 1996).

A liderança situacional parte do pressuposto de que não existe um modo previamente determinado de liderança. Ao líder, cabe avaliar cada situação e dependendo de como o liderado está preparado para enfrentar determinada responsabilidade, define como agir. Este procedimento vai indicar em que nível de experiência o liderado se encontra, para que o líder possa, por meio de ações coerentes, conduzi-lo á condição de assumir sozinho e com disposição, a responsabilidade de executar a tarefa.

O princípio deste método consiste na identificação, por parte do líder, da atual capacidade e da disposição que o liderado possui para dirigir seu próprio comportamento em uma determinada tarefa. A combinação das intensidades da capacidade e da disposição irá indicar o estilo de liderança ou modo de agir mais adequado. Pura e simplesmente, aplicar um estilo de liderança caracteriza-se por uma tentativa do líder de influenciar o comportamento do liderado. Para efetivar a influência do líder e conseqüentemente R. eletr. estrat. neg., Florianópolis, v.4, n.2, p. 181-201, jun./dez. 2011 
conseguir a sujeição do liderado, torna-se necessário identificar qual a base de poder mais indicada para a ocasião. Torna-se necessário, portanto, identificar três elementos que se relacionam para que se realize uma liderança eficaz: 1 - a identificação da capacidade e da disposição para a realização da tarefa; 2 - a definição do estilo de liderança; 3 - a definição da base de poder. A Figura 1 faz a relação dos três elementos.

Figura 1: Relações para liderar de forma eficaz.

Identificação da
Capacidade e
Disposição
Escolha do Estilo de
Liderança
Escolha da Base de
Poder

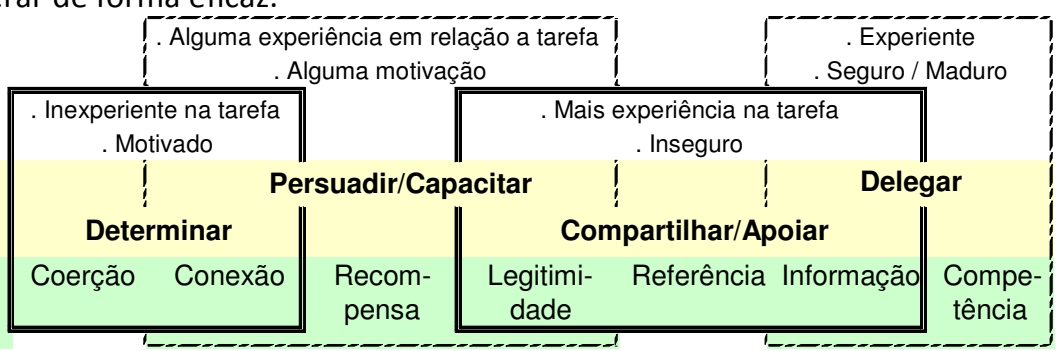

Fonte: adaptado de Goldsmith, Lyions e Freas (2000) e Hersey e Blanchard (1986)(1996).

Ao identificar qual a capacidade e qual a disposição que um liderado possui para executar uma determinada tarefa, o líder encontrará quatro combinações possíveis:

A primeira combinação consiste na falta de experiência, mas, existência de motivação por parte do liderado. Situação característica de colaboradores recém contratados ou que recebem uma nova tarefa muito diferente das habituais. Nestes casos o líder determina a responsabilidade do empregado, estabelece os objetivos, a maneira de atingi-los e o padrão de desempenho. Além disso, torna-se necessário efetivar a posição do líder através dos poderes de coerção e conexão, ou seja, o liderado deve agir da forma determinada para evitar punições ou para evitar seu encaminhamento aos superiores para a prestação de esclarecimentos.

Quando o liderado passa a apresentar alguma experiência e ainda mantém certa motivação é o momento de o líder apresentar o contexto da tarefa. O líder deve explicar e capacitar à tarefa em sua totalidade, procurando escutar o liderado solicitando sua opinião. Nesta etapa, o líder vai assegurar sua liderança através da sua conexão, da possibilidade de oferecer algum incentivo ou apenas pelo entendimento de que a sua posição superior na hierarquia da organização é que prevalece. 
Quando o subordinado apresentar mais experiência na realização das tarefas, porém ainda apresente insegurança, é aconselhável que o líder the dê apoio, discutindo as metas e padrões de desempenho. Estas atitudes farão com que o liderado sinta-se confiante e motivado. Entretanto, para efetivar a liderança, o líder deve utilizar o poder conferido pelo seu cargo, pela sua estima ou pelas informações importantes que ele detém.

A última situação possível, a mais desejada pelos líderes e organizações, é quando o subordinado demonstra responsabilidade e conhecimento da tarefa, estabelece seus próprios objetivos e padrões de desempenho, e ainda mantém um bom canal de comunicação com os colegas e superiores. Ao líder, cabe delegar, ou seja, transferir ao liderado as responsabilidades de decisão e de execução. A efetivação da liderança pelo líder deve ocorrer pela posse de informações importantes ou por intermédio do conhecimento das tarefas.

A adoção de estilos e poderes coerentes ao perfil do liderado desencadeia um processo evolutivo que proporciona o aumento da sua capacidade e disposição elevando a experiência, motivação e autogestão. Por outro lado, a adoção de estilos e poderes ineficazes desencadeia um processo regressivo, que conduz o liderado ao pouco interesse pela tarefa. A figura 2 apresenta as etapas de evolução e regressão proporcionados pela adoção do estilo e poder:

Figura 2 : Processo de evolução ou regressão da capacidade e disposição pela adoção de estilo e poder. adoção de estilos e poderes eficazes

Capacidade e Disposição

\begin{tabular}{|l|l|c|c|}
\hline $\begin{array}{l}\text { Inexperiente } \\
\text { Motivado }\end{array}$ & $\begin{array}{c}\text {. Alguma Experiência } \\
\text {.Alguma Motivação }\end{array}$ & $\begin{array}{c}\text {. Mais experiência } \\
\text {. Inseguro }\end{array}$ & $\begin{array}{c}\text {. Experiente } \\
\text {. Seguro/Maduro }\end{array}$ \\
\hline
\end{tabular}

adoção de estilos e poderes ineficazes

Fonte: Adaptado de Goldsmith, Lyions e Freas (2000)(2003) e Hersey e Blanchard (1986)(1996).

Não é possível prever quanto tempo uma pessoa leva para reagir ao estilo e poder, por conseguinte, não se sabe quanto tempo cada indivíduo permanece em cada nível de experiência. No entanto, entende-se que é possível acelerar o processo de amadurecimento da capacidade e disposição de um subordinado para a realização de uma tarefa, oferecendo atividades de aperfeiçoamento para o trabalho e atividades de aperfeiçoamento comportamentais. 
Apresentadas as técnicas de liderança, encaminha-se ao próximo tópico que descreve o ciclo de tomada de decisão, ou seja, como são as etapas para o desenvolvimento das habilidades de gestão de pessoal num simulador de gestão.

\section{DESENVOLVENDO HABILIDADES DE LÍDER POR INTERMÉDIO DE UM SIMULADOR COMPUTACIONAL}

O modelo pretende desafiar os participantes da simulação a cumprir um novo objetivo além dos já existentes no simulador, o de obter uma melhor performance de produtividade da mão de obra através do uso da teoria da Liderança Situacional associadas a "técnicas de liderança".

Melhores desempenhos produtivos da mão de obra são possíveis através da identificação coerente, por parte do participante da simulação, das reações de um gerente (personagem virtual) e da aplicação eficaz do estilo de liderança e da base de poder. A cada rodada serão apresentadas novas situações relatadas pelo gerente na forma de frases e textos, que sugerem diálogos e que simulam o comportamento de um colaborador. $\mathrm{O}$ participante define suas decisões e a conseqüência de uma boa ou má decisão afetará todos colaboradores da empresa simulada.

Para um melhor entendimento do processo apresenta-se sua representação gráfica, a Figura 3, denominada Ciclo de Tomada de Decisões sobre o Estilo de Liderança e Base de Poder. 
Figura 3. Ciclo de Tomada de Decisões sobre o Estilo de Liderança e Base de Poder.

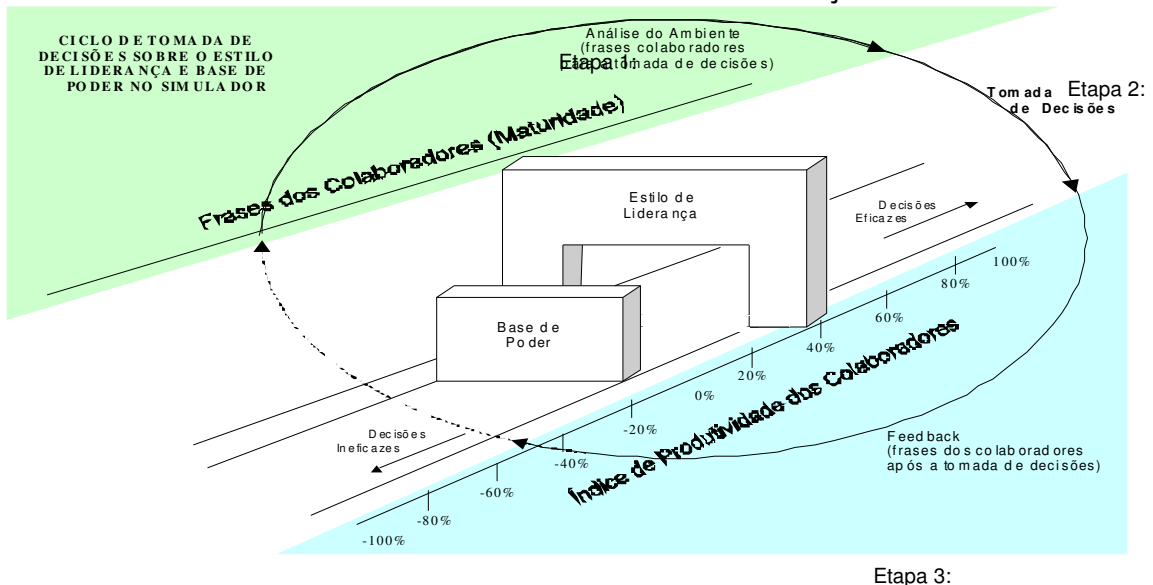

Fonte: adaptado de Gerber, 2006.

Fazem parte de um ciclo de tomada de decisões um participante do simulador no papel de líder e o gerente que é um personagem virtual. As decisões são atribuídas pelo líder ao gerente que vai reagir de forma positiva, neutra ou negativa. As reações do gerente são percebidas através de comentários e frases (feedback's), e pelo índice de produtividade da empresa. Fato de suma importância, é que o gerente passa a ser o elo de ligação entre o líder e os demais colaboradores da empresa. As reações do gerente em relação à aplicação das técnicas de liderança, vão refletir em toda mão de obra e conseqüentemente na produtividade da empresa como um todo. Segue então, a apresentação detalhada das etapas do ciclo:

\section{Etapa 1 - Análise do Ambiente:}

A análise do ambiente é a primeira etapa do ciclo. A análise consiste na leitura e interpretação de relatórios e jornal, ou interface de comunicação do simulador. As frases e comentários do gerente e a produtividade da mão de obra devem ser apresentadas no relatório. Sugere-se a criação de um campo para que sejam informadas as frases do gerente e um campo Produtividade Atual que apresenta o índice de produtividade da mão de obra.

As frases e comentários têm a finalidade de manifestar reações emocionais do gerente em relação a uma tarefa. Estas informações sugerem experiências extraídas do cotidiano vivido na empresa. O objetivo principal das frases e comentários é apresentar os níveis de capacidade e disposição que o gerente possui para realizar a tarefa em questão, subsídios indispensáveis para a definição do estilo de liderança e da base de poder mais R. eletr. estrat. neg., Florianópolis, v.4, n.2, p. 181-201, jun./dez. 2011 
coerentes. Na medida em que o gerente amadurece sua capacidade e disposição, uma nova tarefa é apresentada e recomeça o ciclo.

\section{Etapa 2 - Tomada de Decisões:}

$\mathrm{Na}$ etapa tomada de decisões, momento seguinte à identificação da capacidade e disposição do liderado, o líder deve decidir por um estilo de liderança e um poder que são aplicadas ao gerente. O líder poderá decidir também, se oferece atividades de aperfeiçoamento como reforço ao desenvolvimento do gerente.

Utilizando como base o modelo proposto por Lopes (1993), as opções de estilo de liderança podem ser:

Estilo 1 [Determinar] - Determinar a tarefa, ou seja, dirigir o gerente, dizendoIhe o que fazer, quando fazê-lo e como fazê-lo;

Estilo 2 [Capacitar] - Persuadi-lo a fazer a tarefa, ou seja, dirigir o gerente, dizendo-lhe o que fazer, quando fazê-lo e como fazê-lo, e, ainda, dar apoio ou encorajamento nos seus esforços;

Estilo 3 [Apoiar] - Discutir as idéias com o gerente, ou seja, ouvir o gerente ativamente, dando-Ihe apoio e encorajamento nos seus esforços;

Estilo 4 [Delegar] - Apenas delegar a tarefa para que o gerente resolva.

A etapa tomada de decisões segue com a definição do poder. As opções de poder sugeridas são:

Poder 1 [Coerção] - Agir com o gerente de forma que ele acredite que se não aprender a obedecer as regras do jogo, haverá um preço a pagar.

Poder 2 [Conexão] - Agir com o gerente de forma que ele acredite que se cumprir as ordens eficazmente, ele poderá conseguir vantagens decorrentes da conexão influente que se tem com os superiores dentro da empresa.

Poder 3 [Recompensa] - Agir com o gerente de forma que ele acredite que o cumprimento eficaz de suas ordens lhe trará incentivos em termos de salário, promoção ou reconhecimento.

Poder 4 [Legitimidade] - Agir com o gerente de maneira que ele cumpra suas ordens devido ao cargo que se ocupa na organização e, conseqüentemente, lhe dá o direito de esperar que seus desejos sejam realizados. 
Poder 5 [Referência] - Agir com o gerente inspirando-lhe confiança, proporcionando-Ihe coragem, reconhecimento e outras formas de apoio, para, assim, ter suas ordens cumpridas de maneira eficaz.

Poder 6 [Informação] - Agir com o gerente fazendo com que ele conte com seu líder para esclarecer ou explicar problemas e fornecer-lhe acesso a dados, relatórios e correspondências quando necessário.

Poder 7 [Competência] - Agir com o gerente de maneira que ele perceba que você possui capacidade e os conhecimentos técnicos que ele reconhece como importante.

A etapa tomada de decisão é encerrada com a decisão de oferecer, ou não, atividades de aperfeiçoamento ao gerente. Serão disponibilizados dois tipos de atividades conforme segue:

Atividade de Aperfeiçoamento 1 [Aperfeiçoamento p/ o Trabalho] - Atividades voltadas ao aperfeiçoamento do trabalho. Tem como objetivo desenvolver e adquirir maior grau de instrução e aptidão às habilidades técnicas do gerente. Sua conseqüência é o aumento da capacidade de execução da tarefa.

Atividade de Aperfeiçoamento 2 [Aperfeiçoamento Comportamental] Atividades destinadas ao desenvolvimento e aperfeiçoamento de habilidades técnicas e comportamentais no uso do conhecimento. Tem como objetivo melhorar os relacionamentos interpessoais, desenvolver trabalhos em equipe, melhorar as atitudes e reações em face do meio social, aumentar a autoestima e auxiliar na oratória. Sua conseqüência direta é o aumento da disposição para o trabalho.

Índice de Produtividade dos Colaboradores:

As decisões adotadas pelo líder vão determinar a produtividade do gerente e demais colaboradores da empresa. De acordo com o grau de coerência, as decisões podem variar entre decisões eficazes, neutras ou ineficazes.

- Decisões Eficazes: afetam de forma positiva o índice de produtividade da mão de obra. Sendo assim, a capacidade produtiva da mão de obra varia numa escala de 90 a 100\%. Adotando uma decisão eficaz o líder eleva a capacidade e a disposição do gerente para realizar a tarefa. A empresa que completar o ciclo de desenvolvimento do gerente 
passa a ser premiada com um bônus de produtividade por um período. A Figura 4 mostra o efeito das decisões eficazes.

Figura 4. Efeito das decisões eficazes no ciclo de desenvolvimento e produtividade da mão de obra.

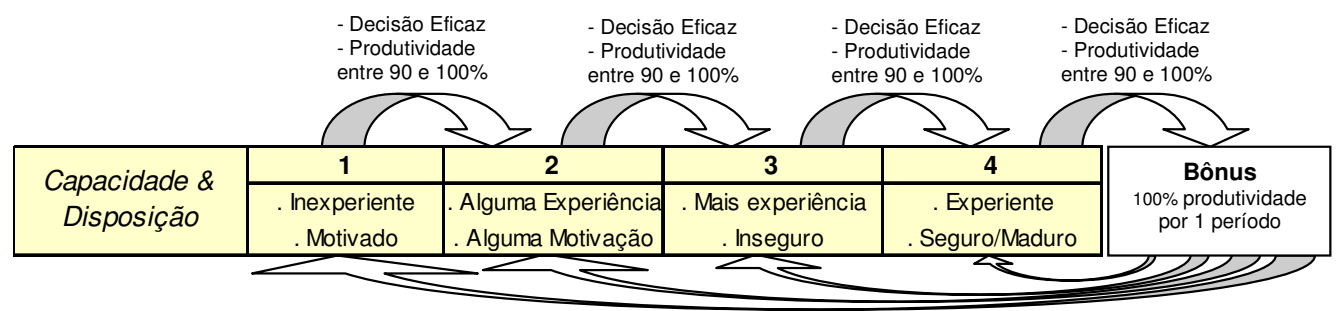

Início dos Novos Ciclos de Desenvolvimento

Fonte: adaptado de Gerber (2006).

- Decisões Neutras: são as decisões que estão próximas das decisões coerentes, mas que precisam melhorar. Neste caso, a capacidade produtiva da mão de obra varia numa escala de 60 a 89\%. A capacidade e a disposição do gerente permanecem a mesmas. A incidência de decisões neutras por mais de dois períodos ocasiona um desgaste do poder e o gerente diminui em uma escala sua capacidade e disposição para realizar a tarefa. A Figura 5 mostra o efeito das decisões neutras.

Figura 5. Efeito das decisões neutras no ciclo de desenvolvimento e produtividade da mão de obra.

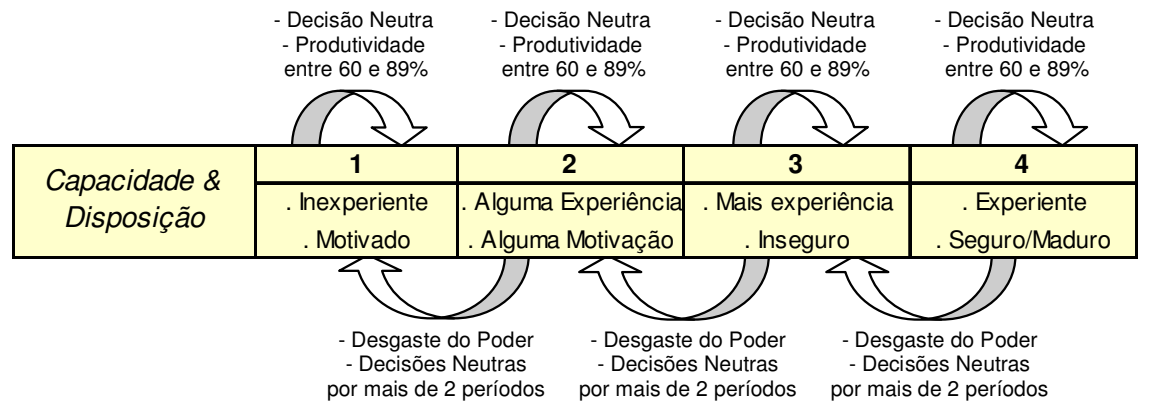

Fonte: adaptado de Gerber (2006).

- Decisões Ineficazes: afetam de forma negativa o índice de produtividade da mão de obra provocando um efeito semelhante à uma "operação tartaruga", ou seja, a capacidade produtiva diminui sensivelmente, mas não a ponto de parar. Neste caso, a capacidade produtiva da empresa será de 55\%. A tomada de decisões ineficazes em dois períodos seguidos diminui em uma escala a capacidade e disposição do gerente. Caso ocorra em três períodos, o gerente solicita demissão. O pedido de demissão causa penalidades mais severas à R. eletr. estrat. neg., Florianópolis, v.4, n.2, p. 181-201, jun./dez. 2011 
empresa, tais como: pagamento dos direitos trabalhistas, multa e diminuição drástica da produtividade por um período mais o tempo necessário para contratar um novo gerente.

Figura 6. Efeito das decisões ineficazes no ciclo de desenvolvimento e produtividade da mão de obra.

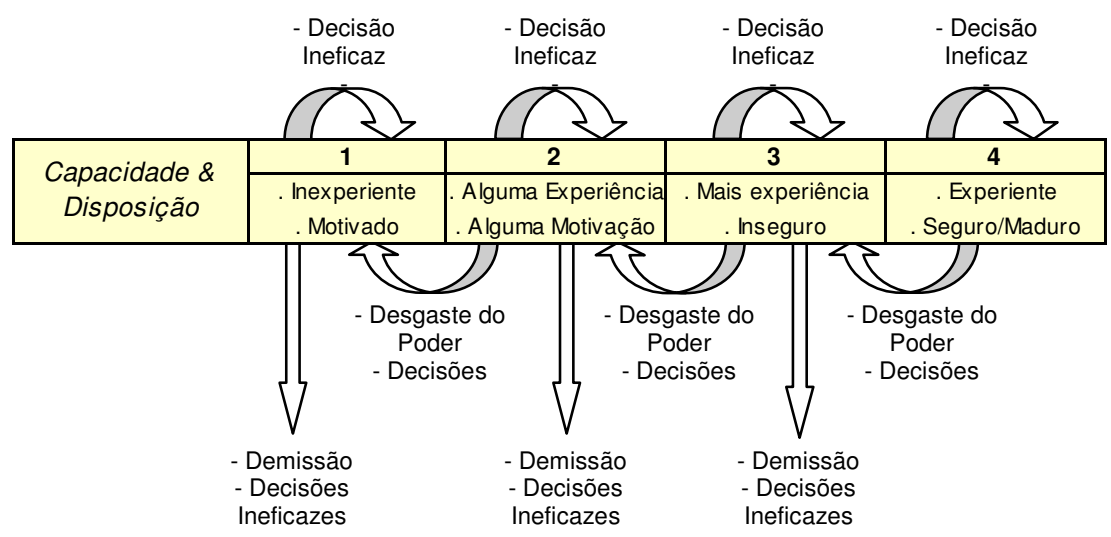

Fonte: adaptado de Gerber (2006).

\section{Etapa 3 - Feedback:}

Comentários dos gerentes sobre o estilo de liderança e poder adotados no período anterior, serão fornecidos para a avaliação da decisão adotada no período anterior. Os comentários, bem como o índice de produtividade da mão de obra, serão os elementos que preparam os líderes para a próxima rodada.

\section{ESTUDO DE CASO: O GI-MICRO E OS FATORES HUMANOS}

Assim como ocorre em outros simuladores de gestão, tais como GI-EPS (gestão industrial), GS-ENE (gestão de pequenas e micro empresas), GEBAN (gestão de agências bancarias), GP-1 (gestão da produção) e as versões do LSSP_PCP (dinâmicas de PCP); o modelo GI-Micro avançou nas áreas exatas da administração, porém, em questões como comportamento dos colaboradores e gestão de pessoas, tão importantes ao entendimento das boas práticas administrativas, ainda demonstra certa carência. Neste contexto, esse tópico apresenta o estudo de caso, onde são analisados os aspectos relacionados às pessoas 
e é traçado um caminho para tornar o modelo GI-Micro ainda mais próximo da realidade das empresas reais agregando, pois, a simulação da liderança em seu ambiente simulado [TUBINO (2007); GERBER (2006); LACRUZ (2004); DETTMER (2001)].

No micro mundo simulado do GI-Micro, os participantes são desafiados a gerenciar uma empresa, tomando decisões referentes às áreas financeira, de produção e de marketing. A dinâmica exige a análise de relatórios e balanços, além do planejamento estratégico e controle da utilização dos recursos materiais disponíveis nas empresas virtuais. $\mathrm{O}$ ambiente permite aos participantes interagir com o universo empresarial, com desafios realistas, porém com um grande diferencial, tudo sem comprometer os recursos de uma empresa de verdade. Informações detalhadas do jogo de empresas GI-Micro estão publicadas nos trabalhos de Kopittke, 2000, Mecheln (1997) e (2003), Dettmer (2001), Gerber (2000) e (2006), Hermenegildo (1996) e (2002). Os autores, além de apresentar aspectos como o ambiente, os métodos, os equipamentos, as tecnologias empregadas, os materiais didáticos, os modelos matemáticos e o pessoal envolvido na aplicação do jogo, apresentam também seu histórico e algumas das mais recentes contribuições ao modelo. No entanto, seguindo aos propósitos deste estudo, identifica-se aqui apenas a abordagem dos aspectos humanos do simulador, assunto que será tratado a seguir.

O simulador de gestão de empresas GI-Micro em sua versão sem o modelo de liderança prevê aspectos isolados relativos à gestão de pessoas, que refletem muito pouco ou quase nada a complexidade das relações interpessoais e suas conseqüências. Segue lista de aspectos relacionados a gestão de pessoas no jogo GI-Micro identificados e analisados:

- Quadro de Funcionários: as empresas começam o jogo com 10 empregados trabalhando em ritmo normal, com as mesmas habilidades e conhecimentos, sem a necessidade de capacitação, supervisão ou outra intervenção por parte dos administradores. A única exceção é a possibilidade de escolha do ritmo de operação, ou seja, a quantidade de tempo que os colaboradores devem trabalhar, denominada "horas-extras";

- Produtividade da Mão de Obra: o jogo prevê que com o decorrer do tempo os colaboradores adquirem experiência no trato com as máquinas e na execução das tarefas. 0 modelo assume que a cada 5.000 unidades produzidas a produtividade da mão de obra aumenta em torno de $1 \%$;

R. eletr. estrat. neg., Florianópolis, v.4, n.2, p. 181-201, jun./dez. 2011 
- Salário: é uma variável administrada pelo animador. Tem como finalidade servir como base de cálculo para as horas extras, indenizações trabalhistas e despesas de produtividade. Pode servir como argumento à greve e à operação "tartaruga", nestes casos aumenta a complexidade da gestão de pessoal por afetar a capacidade produtiva das empresas e exigir negociações entre o diretor de produção e o animador;

- Contratação: os colaboradores contratados têm o mesmo perfil dos colaboradores que começam o jogo, ou seja, começam em ritmo normal sem a necessidade de treinamento ou supervisão. $\mathrm{O}$ animador define quantos colaboradores estão disponíveis para a contratação e em que períodos. Contratações têm finalidade única de aumentar a capacidade produtiva das empresas;

- Demissão: assim como a contratação, sua escolha influencia apenas aspectos inerentes a empresa e não aos funcionários. Para cada funcionário demitido deve-se contabilizar o pagamento de uma indenização correspondente ao salário de meio período. A demissão tem como conseqüência a diminuição na capacidade produtiva da empresa.

- Greve: variável administrada pelo animador, tem como objetivos alterar a capacidade produtiva da mão de obra da empresa para forçar um aumento salarial e propiciar a realização de vivências de negociações. Suas conseqüências às empresas do jogo são a diminuição da capacidade produtiva e aumento das despesas de produtividade;

- Operação Tartaruga: variável semelhante à greve, porém com intensidade de paralisação dos colaboradores menor. Geralmente a capacidade produtiva é diminuída em até $25 \%$. Do ponto de vista da modelagem, greve e operação tartaruga são uma coisa só.

Observa-se na lista de características anteriores, que algumas competências como o traquejo interpessoal exigido para influenciar e energizar pessoas, a capacidade de mudar de atitude de acordo com o comportamento das pessoas e o respeito por indivíduos de distintas origens e formações, não são contemplados no modelo original do Gl-Micro. Trata-se, pois, de um ambiente propício à implementação do modelo de liderança de pessoas.

Como adequações ao GI-Micro e outros simuladores que venham a utilizar o modelo aqui proposto, além da incorporação do Ciclo de Tomadas de Decisões sobre Estilo de Liderança e Base de Poder, sugere-se o uso de uma planilha de monitoração da liderança, R. eletr. estrat. neg., Florianópolis, v.4, n.2, p. 181-201, jun./dez. 2011 
o uso da metodologia prototipação para o desenvolvimento de interfaces como janelas e relatórios que são responsáveis pelas informações de entrada e de saída do sistema; a modelagem matemática preliminar, responsável pelo processamento de dados; elaboração de um elenco de frases, relacionadas ao trabalho e ao feedback que demonstram a capacidade e a disposição de um colaborador virtual e suas percepções em relação ao líder.

\section{CONSIDERAÇÕES FINAIS}

Para finalizar, consideram-se as reflexões sobre a problemática existente em torno do desenvolvimento de habilidades e competências de liderança de pessoas nos simuladores de gestão computacionais.

Dentre as técnicas e práticas pesquisadas, o modelo de Liderança Situacional de Paul Hersey, demonstra aptidão à modelagem matemática e contempla as características de um simulador de gestão de empresas permitindo desenvolver mecanismos de decisões que correspondam à expectativa de simular a administração de pessoas em um ambiente computacional, tal qual foi apresentado no tópico Desenvolvendo Habilidades de Líder num Simulador Computacional, onde foi apresentada a proposta de ciclo de tomada de decisões sobre estilo de liderança e base de pode num simulador.

No que tange ao modulo GI-Micro, ambiente laboratório deste estudo, após uma análise em busca de abordagens dos aspectos humanos, tanto no ambiente formado pelos participantes, quanto no ambiente virtual simulado, foi possível demonstrar que, embora existam aspectos humanos sendo tratados no modelo, há espaços para conceber novos aspectos específicos da função de líder, principalmente no que diz respeito ao modelo matemático.

Tomando-se por base a técnica de liderança escolhida, o processo aqui organizado e proposto, o exemplo do ambiente do GI-Micro, a conclusão deste estudo é que o modelo de liderança de pessoas é viável, não vai aumentar de forma excessiva a complexidade do simulador de gestão de empresas e vai abordar temas pertinentes a R. eletr. estrat. neg., Florianópolis, v.4, n.2, p. 181-201, jun./dez. 2011 
formação de gestores cada vez mais completos com uma didática que vai aumentar a excelência do simulador.

\title{
MODEL OF LEADERSHIP OF SIMULATORS FOR PEOPLE MANAGEMENT
}

\begin{abstract}
In the teaching of business management practices, the simulators have a managerial role, especially when the goal is to use teaching tools and tools for teaching and learning engaging, practical and dynamic. The universe versions of simulators and management areas addressed by them is large, however, versions that cover only exact areas of the administration are still observed more frequently, because neglecting the human aspects of business management. Therefore, this article presents a model for the simulation of corporate computing, whose aim is to provide participants with the development of managerial skills and competencies related to leading people. For this purpose, we studied techniques and practices of people with leadership potential and computational modeling were developed a model and a process of decision making for management simulators. The article follows with the presentation of a case study and is completed with the results and conclusions.
\end{abstract}

Key-words: business simulators. Human behavior. Leadership.

\section{REFERÊNCIAS}

BARBEIRO, Heródoto. Falar para Liderar. São Paulo: Futura, 2003. 
BELASCO, James A.; STAYER, Ralph C. O vôo do búfalo: Decolando para a excelência, aprendendo a deixar os empregados assumirem a direção. Rio de Janeiro: Campus, 1994.

BELL, Chip R. The mentor. Training \& Development. Volume 54, Edição 2, Pag. 52. Fevereiro, 2000.

BIGDON, Christine; KORF, Benedikt. The Role of Development Aid in Conflict Transformation: Facilitating Empowerment Processes and Community Building. Berghof Research Center for Constructive Conflict Management, Berlim - Alemanha, 2004.

CHIAVENATO, Idalberto. Construção de talentos. Rio de Janeiro: Campus, 2002.

COUTU, Diane L. Líderes no divã. Harvard Business Review, p. 53, Janeiro, 2004.

DETTMER, Armando L. Concebendo um laboratório de engenharia de produção utilizando um jogo de empresas. Tese de doutorado em Engenharia de Produção/UFSC. Florianópolis, 2001.

DORIA, Joyce; ROZANKSI, Horacio; COHEN, Ed. O que as empresas esperam dos MBAs. HSM Management, p.136, março-abril, 2004.

FIATES, Gabriela G.S.; NASCIMENTO, Ana D.R.; FIATES, José E.A. Uma estratégia para a gestão de pessoas em organizações de conhecimento: uma experiência da gestão de competências em um instituto de pesquisa e desenvolvimento. Revista Estratégia e Negócios, Florianópolis, v. 2, n. 1, jan./jun. 2009.

FIORELLI, José O. Psicologia para administradores: integrando teoria e prática. São Paulo: Atlas, 2003.

FREAS, Alyssa; SHERMAN, Stratford. O território selvagem: do coaching de executivos. São Paulo: Harvard Business Review, novembro, 2004.

GERBER, Juliano Z. Proposta de metodologia para o desenvolvimento de recursos à aplicação de jogos de empresas via internet - O modelo para o jogo de empresas GI-EPS. Dissertação de mestrado em Engenharia de Produção/UFSC. Florianópolis, 2000.

GERBER, Juliano Z. Jogo de Empresas e a Formação de Líderes Empresariais. Tese de Doutorado em Engenharia de Produção - Universidade Federal de Santa Catarina, 2006.

GERSTBERGER, Richard L.; GROMALA, Karen A. How effective is utility leadership? Journal American Water Works Association. Volume 102, Pag. 46, Janeiro, 2010.

GOLEMAN, Daniel. What makes a leader? Harvard Business Review, Volume 82, Pag. 82. Janeiro, 2004. 
GOLDSMITH, Marshall; LYONS, Laurence; FREAS, Alyssa. Coaching for Leadership - How the World's Greatest Coaches Help Leaders Learn. USA: Jossey-Bass/Pfeiffer, 2000.

GOLDSMITH, Marshall; LYONS, Laurence; FREAS, Alyssa. Coaching: o exercício da liderança. Rio de Janeiro: Elsevier:DBM, 2003.

HERMENEGILDO, Jorge L.S. A utilização da padronização como ferramenta da qualidade total para o desenvolvimento de jogos de empresas. Dissertação de mestrado em Engenharia de Produção/UFSC. Florianópolis, 1996.

HERMENEGILDO, Jorge L.S. O uso da abordagem por competências no desenvolvimento de jogos de empresas para a formação de empreendedores. Tese de doutorado em Engenharia de Produção/UFSC. Florianópolis, 2002.

HERSEY, Paul; BLANCHARD, Kenneth H. Revisiting the life-cycle theory of leadership. Training \& Development. Volume 50, Pag. 42. Janeiro, 1996.

HERSEY, Paul; BLANCHARD, Kenneth H. Psicologia para Administradores. São Paulo: E.P.U., 1986.

HESSELBEIN, Frances; COHEN, Paul M. De líder para líder. São Paulo: Futura, 1999.

JUCHEM, Dionise M.; ROSSATI, Willina R.; GOMES, Narciso B. Gestão de Pessoas: O perfil das boas organizações para se trabalhar. Revista ADMpg: Gestão Estratégica. Volume 4, Pag.131. Setembro, 2011.

KOPITTKE, Bruno Hartmut et alli. Jogo de empresas GI-EPS: manual do jogador. Apostila editada no Departamento de Engenharia de Produção e Sistemas/UFSC, 2000.

KOPITTKE, Bruno Hartmut et alli. Liderança e motivação para a qualidade. Apostila editada no Departamento de Engenharia de Produção e Sistemas/UFSC, 2000.

LACRUZ, Adonair J. Jogos de empresas: considerações teóricas. Caderno de pesquisas em administração, Volume 11, Edição 4, Pag.93.Dezembro, 2004.

LANER, Aline S.; CRUZ Jr., João B. Repensando as organizações: Da formação à participação. Florianópolis: Fundação Boiteux, 2004.

LOPES, Mauricio C. LIDER: Manual de operação do sistema. Florianópolis, EPS/UFSC, 1993. MECHELN, Pedro J. V. Jogo de empresas, ambiente interativo e agentes computacionais mediadores. Tese de doutorado em Engenharia de Produção/UFSC. Florianópolis, 2003. 
MECHELN, Pedro J. V. SAP1-GI: Sistema de apoio ao planejamento no processo de tomada de decisão do jogo de empresas GI-EPS. Dissertação de mestrado em Engenharia de Produção/UFSC. Florianópolis, 1997.

NAVARRO, Peter. Nota zero em liderança. Harvard Business Review, p. 11, Dezembro, 2004.

NELSON, Robert B. Delegar: Um passo importante, difícil e decisivo. São Paulo: Makron Books, MacGraw-Hill, 1991.

PORCHÉ, Germaine; NIEDERER, Jed. Coaching: O apoio que faz as pessoas brilharem. Rio de Janeiro: Elsevier, 2002.

REIS, Dayr A.; SILVA, Paulo A.L. Os ventos das mudanças: simbiose entre engenharia e administração. Revista de Ensino de Engenharia. Vol.23, Num. 1, p. 11, Junho, 2004.

SILVA, Edna L.; MENEZES, Estera M. Metodologia da pesquisa e elaboração de dissertação. 4 . Edição. Florianópolis: UFSC, 2005.

SMITH, Jerry; GOLDEN, Peggy. The Human Resource Management Simulation. Disponível em: <http://wps.prenhall.com/bp_smith_simulation_all>. Pearson Education. New Jersey USA, 2005.

TUBINO, Dalvio F. Planejamento e Controle da Produção: teoria e prática. Editora Atlas, São Paulo, 2007. 